\title{
Semiotica do triangulo de Grocco
}

\author{
Dr. Eduardo Monteiro (Assistente \\ extraordinario do Prof. Rubião \\ Meira)
}

Em 19012, Grocco, professor em Florença, descreveu na parede posterior do torax uma massicez apresentando a forma de um triangulo rectangulo, situada do lado opposto aos derrames liquidos da pleura. Conferiu-lhe o titulo de "triangulo paravertebral oposto" e, segundo a sua opinião, seria patognomonico das colecções pleu rais, com o mesmo valor de uma punção exploradora, assim servindo para diferençal-as dos outros estados morbidos que igualmente determinam uma massicez na zona comprometida, parecer que - veremos em tempo oportuno - não representa a realidade dos factos.

Como obra de justiça, asinale-se que antes de Grocco o referido sinal já era conhecido à Rauchiuss, desde 1996, e a Koranyi no ano seguinite, porém ao professor de Florença, que ignorava os trabalhos anteriores, cabe inquestionavelmente 0 merito de o tornar conhecido em todo o mundo medico.

O triangulo de Grocco, ou Rauchfuss - Koranyi - Grocco, ou sinal de Grocco, ou triangulo paravertebral oposto, ou massicez triangular, ou massicez paravertebral, existe efectivamente nos derrames pleurais, é digno de consideração, muito embora Barbieri afirmasse nunca o ter enicontrado, e Bérnard, Roch is Dufour declarassem que não merece importancia.

O lado interno do triangulo é representado pela linha espondilea, o inferior pelos confins pulmonares, e o externo vae em direção obliqua de cima para baixo e de dentro para fora reunindo as duas extremidades da figura geometrica. Tem, portanto, um cateto perpendicular e outro horizontal, e a hipotenusa inclinada.

Para se determinar o triangulo de Grocco, o individuo fica de pé ou sentado, e percute-se levemente de fora para dentro e de cima para baixo, em linhas obliquas ao raquis. A percussão forte, para este fim, não é conveniente, porquanto, assim procedendo, muitas vezes passará desapercebida esta zona de obscuridade.

Consoante a opinião da maioria dos observadoreș, o apice do triangulo alcança o nivel da massicez do lado oposto, e são tidos como erroneos os pareceres contrarios, como o de Rauchfuss, o de Teissier, que o encontraram abaixo, como o de Schittenhelm, que o demarcou acima.

A extensão da base varia proporcionalmente á grandeza da massioez do lado oposto, e vae de 3 a 7 centimetros,

A area do triangulo está sujeita a sofrer modificações conforme a posição do paciente, Si ele se deita sôbre o lado doente, a massicez paravertebral pode tender a diminuir e é mesmo susceptivel de desaparecer. Si ele assume o deculbito do lado são, propende para aumentar. Condição, entretanto, indispensavel para se produzirem alterações da area sob o dominio do decubito, é a exiştencia de um derrame pleural dota'do de extrema mobilidade, falhando quando a causa eficiente do triangulo é uma outra apresentação morbida, ou todas as vezes que a collecção liquida é immovel, como sóe acontecer no momento em que é demasiado grande ou então enquistada. 
Sob a influencia da inspiração, Goldscheider teria observado a diminuição da sua superficie, e sob o influxo da expiração o seu aumento. Este reparo não foi, todavia, confirmado pelos demais auctores, ainda que ordenassem movimentos respiratorios extensos e profundos.

No tocante ao grao da massicez, ela vai-se incrementando de cima para baixo e de fora para dentro, é mais intensa nas zonas internas e inferiores.

A' percussão digito-digital, alem da informação acustica que nos fornece, que é a hipofonese, recolhemos ùma sensação tactil, igualmente preciosa, que vem a ser o aumento da resistencia da parede.

Não asøiste razão a Grocco no informar que o seu triangulo seria formado de preferencia quando a massicez oposta se assesta no hemitorax direito, pois observações inconcussas demonstram ser indiferentemente delimitado de um ou outro lado.

$\mathrm{Na}$ area do triangulo de Grocco, dois fenomenos fisiologicos atenuam-se ou desaparecem - o fremito toraco-vocal e o murmurio vesicular - e tres ocorrencias patologicas podem surgir: a pectoriloquia afonica, e egofonia e o sinal de Pitres (signe du sou).

Controversos são os resultados da radioscopia da zona correspondente á massicez paravertebral, e são pobres os estudos a respeito. Emquanto que Mosler, Jürgens, Schittenhelm observavam uma sombra, Goldscheider nada viu na chapa fluorescente, acreditando que o triangulo se escondia atraz da coluna vertebral. Todav́ia, a constatação de uma sombra nada significa, porquanto pode muito bem correr por conta do desvio do coração. A este respeito é instrutivo um caso de Mosler; tratava-se de um individuo portador de um pleuriz esquerdo com derrame e triangulo de Grocco correspondente. no qual havia uma obscuridade radioscopica á direita em relação com o desvio do motor candiaco, obscuridade que persistiu após a evacuação da coleção liquida e após o desaparecimento da maśsicez paravertebral, porque, não obstante o esvasiamento da pleura, a deslocação do orgão central da circulação continuava ainda.

No caso em que existe um derrame pleural bilateral - cada qual a um mivel diferente - será observado o sinal de Grocco do lado em que estiver colecionada menor quantidade de liquido, constituindo o que se chama triangulo paravertebral diferencial. A altura dêste será, então, igual á diferença de nivel de ambos.

o triangulo de Grocco não será confundido com a massicez cardiaca posterior, com a que pode ser determinada pela auricula esquerda ou pela direita, respectivamente de cada lado da coluna vertebral; o engano é facil die ser evitado desde que se tenha em consideração o facto da forma da figura de hipofonese, neste caso, não ser triangular, mas sim quadrangular, alem de que o seu bordo inferior fica em nivel elevado, distante dos confins pulmonares.

E' importante saber-se quie no pneumotorax, na mesma séde da massicez paraventebral, vamos encontrar um triangulo de hiperfonese quasi timpanica. As observações de Araoz Alfaro, Miguel Couto, Jacintho de Barros, Bierraccini, Murguet, assim o atestam. No caso do Prof. Miguel Couto, o individuo, portador de um pneumotorax. apresentava um triangulo timpanico paravertebral, que ulteriormente se transformou em triangulo massiço, quando pus se coleccionou no interior da cavidade pleural. Facto inverso sucedeu no doente de Jacintho de Barros; sofria de um pleuriz com derrame. 
apresentando o triangulo de massicez, que se transformou em triangulo de hipofonese logo que o autor nelle praticou um pneumotorax artificial.

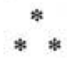

Assim conhecido o triangulo de Grocco, vejamos em que ocorrencias clinicas o deparamos.

Já vimos que, no parecer de Grocco, a constataçãa do seu triangulo seria um sinal patognomonico de derrame da pleura, teria 0 mesmo valor de uma puncção exploradora e valeria como elemento decisivo para eliminar o diagnóstico de uma hepatisação do pulmão, de uma pneumonia massiça, de um tumor pulmonar, pleural ou pleuro-pulmonar. No emtanto assim não é. O que está hoje assentado é que o triangulo de Grocco se apresenta todas as vezes que existe uma massicez na parede toracica posterior alcançando o raquis, seja a causa da hipofonese de séde supra ou infra-diafragmatica, pouco importa. As observações comprobadoras dêste acêrto são copiosas. Na pneumonia foi registrado por Hollis, Hamburger, Clerigo, e, entre nós, pelo Prolf. Miguel Couto e pelo Dr. Eiduardo Rodrigues Alves. No quisto hidatico do figado foi verificado por Bérnard, no abcesso peri-nefretico por Ewart, num caso de coleç̧ão purulenta sub-frenica por Beall.

Diante dêstes factos demonstrativos da existencia do triangulo de Grocco em estados outros que não o derrame pleural, pensou-se que as modificações da área da figura geometrica sob a influencia dos decubitos lateraes seriam sinal certo de colecção liquida no interior da pleura. De facto, o encontro desta variabilidade da superficie do triangulo fala a favor de um pleuriz exsudativo ou de hidrotorax, porem a fixidez da área não constitue absolutamente elemento pro ou contra, porquanto - já dissemos atraz - os proprios derrames podem apresental-a quando são immoveis, graças á sua grande copia ou ao seu enquistamento.

Erronea deve ser a observação de Vignola, em que apresenta um pleuriz, a principio seroso e mais tarde purulento, com triangulo de Grocco no primeiro periodo ie desaparecimento no segundo. Os factos de Miguel Couto e Araoz Alfaro, entre outros, mostram exuberantemente que a massicez triangular existe por igual nos empiemas e não é privativo dos derrames serosos.

Para algunı, o triangulo de Grocco existiria em condições fisiologicas; para Roch e Dufour em individuos สãos, para Smithies em mulheres gravidas.

Dizem Roch e Dufour que encontraram, de cada lado da coluna vertebral, uma fita de massicez alargando-se na base; esta hipofonese, eles atribuem-na lá presença dos musculos alojados nas goteiras vertelbraes, e- a sua maior extensão na zona inferior ligam-na ao espessamento progressivo, de cima para baixo, das massas musculares. Assim, pois, segundo estes observadores; o triangulo de Grocco nada mais seria do que esta faixa paravertebral, tornada unilateral mercê d'uma massicez toracica.

Entretanto, o parecer de Roch e Dufour não procede, porquanto são eles os primeiros a dizer que a delimitação da 'sua figura exige uma percussão demasiado atenta, que a submassicez é subtil, que os contornos são difusos e não nitidos e precişos. Demais, observadores cuidadosos e insuspeitos atestam que: a massicez paravertebra? é nitidamente triangular e não em forma de faixa. 
Outros argumentos poderosos militam contra as ideas de Roch e Dufour. $\mathrm{Si}$ o triangulo de Grocco fosse um fenomeno fisiologico, não se compreenderia como a altura do seu apice varia consoante sobe ou abaixa o nivel da massicez do lado oposto: Si fosse um facto normal, não teria explicação a possivel variabilidade da sua área de acôrdo com os decubitos. Finalmente, si não fosse patologico, ficaria insoluvel a transformação do triangulo de massicez em identica figura geometrica de sonoridade no pneumotorax.

$\mathrm{Na}$ gravidez, Smithies teria deparado uma massicez semelhante á descrita por Grocco Começaria na base direita, teria um apice na linha espondilea é iria terminar no lado esquerdo, com um bordo inferior maior que o do triangulo do profiessor de Florença. A sua causa estaria no deslocamento do figado para cima determinado pelo utero, e desaparecendo logo que esite orgão exonerasse o seu conteuda.

Numa tese do Rio de Janeiro, o Dr. Attila Torres mostra-se de acôrdo com Smithies a respieito da existencia da referida massicez, e diz que encontrou um triangulo isosceles de tal modo disposto que a linha espondilea representava a sua bissetriz; diz mais que o deparou somente no nono mez da gravidez e que o seu ápice sempre se mostrava ao nivel da setima vertebra dorsal.

O triangulo de Smithies, portanto, de acôrdo com a descrição do seu autor e com a de Attila Torres, é assás diferente do triangulo de Grọcco. O primeiro é um triangulo isosceles, é mediano, a sua base toma as duas regióe paravertebraes, direita e esquerda, e possue uma bissetriz representada pela linha das apofises espinhosas. O segundo é um triangulo rectangulo, é lateral e não mediano, e a linha espondilea constitue o seu cateto perpendicular e não a bissetriz.

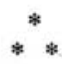

Assim estudado o triangulo de Grocco, vejamos como interpretal-o, qual a sua exacta semiogenese.

Pensou-se que se o poderia explicar pela passagem do fundo de sacco paravertebral da pleura, o recessus paravertebralis, de um para o outro lado da coluna raquiana, migração determinada pela presença do liquido no interior da cavidade da serosa. E' verdade que esta concepção pode elucidar a forma geometrica da massicez, porquanto o deslocamento seria mais acentuado nas partes inferiores, graças á pressão crescente, de cima para baixo, que o liquido exerce sôbre a pleura; é exacto que seria capaz de interpretar, pelo mesmo mecanismo, a formação de um triangulo timpanico paravertebral no pneumotorax. Mas o que esta theoria não aclara é a existenciat do triangulo de Grocco em casos que absolutamente não trazem motivo para um recalcamento da serosa, como na pneumonia e no 'paquipleuriz. Alem de que, tal desvio não foi demonstrado por qualquer forma, nem tampouco recébeu a sanção da radiologia. Assim, pois, esta teoria deve ser posita de margem, como inaceitavel e como incapaz de explicar todos os factos.

Para Teissier, a massicez paravertebral seria devida a uma dilatação da auricula direita, por sua vez determinada por um embaraço na pequena circulação, por um disturbio hidraulico subsidiario de um derrame pleural ou de uma pneumonia. Conforme as suas ideas. o triangulo estaria sempre filiado ao aumento de volume deste reservatorio cardiaco, porêm a causa immediata seria variavel con- 
forme o sinal de Groco fosse deste ou daquele lado. Si estivesse á direita, nada mais representaria senão a projecção pleşica, pura e simples, da dilatação da atrio homolateral, emquanto que, si a sua séde fosse á esquerda, o factor proximo residira no intimo contacto entre a mesma auricula e o raquis, fazendo com que este vibrasse menos quando se realizasse a percussão.

Apezar de engenhosa, a teoria de Teissier não póde ser aceita por numerosos motivos. Primeiramente, a massicez obtida pelo professor de Lyon possue quatro faces e não trez, e assim o quadrangulo de Teissier não é a triangulo de Grocco. Si este argumiento poderoso não fosse convincente, bastaria atender a que a hipofonese de origem cardiaca posterior é muito menos acentuada que a atinente ao Isinal de Grocco, que aquela fica situada muito acima, dentro de duas linhas, uma passando pela 5.a e outra pela 8.a vertebra dorsal, que não sofre variações de superficie confforme os decubitos, como é frequente na massicez triangular, e, por fim, que a hipotes de Teissier é incapaz de esclarecer a formação do timpanismo paravertebral no pneumotorax.

LA um eøpirito desprevenido parecerá exacta a teoria que interpreta o triangulo de Grocco como resultante de um desvio dos orgrãos do mediastino, ocasionado pelos derrames pleurais, tanto mais que ela parece, á primeira vista, robustecida pelas experiencias de Baduel e Siciliano. Estes autores escolhiam cadaveres de individuos que nada apresentavamı para o lado do aparelho respiratorio, e, com um soluto de gelatina a $1.5 \%$, praticavam uma injecção na cavidade abdominal, com o fito de obterem uma pressão identica á do vivo, e uma outra na pleura, com o intento de realizarem as condições de um derrame. Feito isto, á medida que a solução ia invadindo a cavidade pleural, percutiam a região paravertebral oposta e notavam a formação de um triangulo, cujo apice acompanhava o nivel da camada liquida, e cuja base, e portanto tambem a area,, augmentava na proporção direota do derrame artificial. Appós esta averiguação, praticavam uma janela na zona da massicez paravetrebral e constatavam, pela inspecção e pela apalpação, o desvio dos orgãos do mediastino, de preferencia da aorta nos derrames á direita, com primazia do esofago na experiencia feita á esquerda. Não pararam aqui, e, para levarem o apuro ás suas experiencias, realizaram cortes transversaes do torax endurecido, obtendo resultados identicos, observando sempre a deslocação do mediastino.

Embora estes experimentos se revistam de uma aparencia de perfeição, defeitos se lhes podem arguir. Basta lembrar que a rigidez cadaverica cerceia a elasticidade das paredes e das visceras, e que a injecção de liquido no interior da cavidade abdominal recalca para cima a diafragma, condições estas que forçosamente fazem aumentar a pressão intra-pleural, de tal maneira excessiva que não encontra paridade manometrica ém vida. Estas círcumstancias são, portanto, de molde a provocar um desvio do mediastino e assim não admira que Baduel e Siciliano o deparassem em seus ensaios.

N' que, neste particular, as experiencias aesim dirigidas não padem interpretar fielmente o que se passa no doente, o derrame artificial sendo instantaneo e violento em se formar, emquanto que o natural é moroso na sua constituição, dando tempo e azo a que se realize uma adaptação, uma acomodação do seu meio, do seu continente, por via de uma queda da tonacidade do diafragma e dos musculos intercostaes.

Mas, deixando mesmo de banda a critica dos experimentos basicos de Baduel e Siciliano, sobre que tem pedestal a teoria inter- 
pretativa do triangulo de Grocco como sendo este a resultante de um desvio dos orgãos do mediatino, veremos que ela não responde a certas objecções. Em primeiro logar de maneira alguma pode explicar o aparecimento da massicez triangular na pneuomnia, no paquipleuriz, estados morbidos que em absoluto não podem causar um desvio do mediatino. De mais, a 'teoria é contradictoria, pois, si o derrame pleural deslocasse este compartimento toracico e trouxesse, por tal motivo, uma massicez de forma triangular, por que então o pneumo-torax, que seguramente o rechassa, não determina similhante hipofonese, mas, pelo contrario, traz comsigo um timpanismo paravertebral?

Como se vê, é esta mais uma teoria inadmissivel, e custa a crer como ainda seja aceita no Velho Continente.

Modalidade da precedente interpretação é a que foi aventada por Goldscheider, segunda a qual o triangulo seria devido a um desvio do mediastino, conjugado a uma ateleatasia do tecido pulmonar visinho. Incide, portanto, na mesma critica.

Unica rigorosa e capaz de resolver todas as questões atinentes ao tríangulo de Grocco é, como veremos, a do Prof. Miguel Couto.e Dr. Eduardo Rodrigues Alves.

Estes autores nacionaes tambem realizaram ensaios cadavericos, como Baduel e Siciliano, porem os seus experimentos são mais rigorosos, os artificios aproximam-se mais do que se passa em natureza, e, sobretudo, afastaram-se de produzir derrames violentos que alteram fundamentalmente as conclusões a se inferir.

Escolheram igualmente cadaveres de individuos que apresentassem integro o seu áparelho respiratorio, e neles produziam condições fisicas semelhantes láquelas em que é de observação o triangulo de Grocco.

Numa experiencia, após a abertura do torax, retirando sómente o esterno e a verifficação, por meio da apalpação, de que não havia sinequias e que os orgãos do mediastino se encontravam na sua séde normal, introduziam panos enchareados de agua na cavidade pleural. Procedendo á percussão, encontravam, do lado da manobra, o som hidrico classico, e, da banda oposta, o triangulo de Groaco tipico. Por fim, abrindo largamente a caixa toraxica, iam indagar si os orgãos do mediastino foram deslocados pela introducção dos paños molhados. Não encontraram o menor desvio. Releva notar que tudo isto foi praticado tanto no hemitorax direito como no esquerdo, sendo sempre os resultados identicos.

Outra experiencia consistia em injectar, muito lentamente, 3 11tros de agua pura na. cavidade pleural, na altura do 4.0 intercosto, o cadaver conservado sentado. A' medida que o liquido ia alagando a serosa, percutiam, na zona [paravertebral oposta, e encontravam o triangulo de Grocco. Finalmente, na area desta figura geometrica, espetavam agulhas compridas, para se assegurarem si o mediastino fôra desviado, e, abrindo amplamente a arca toracica, averiguavam que todas elas se encontravam encravadas no pulmão do lado oposto ao experimento, e lque, portanito, nenhum dos orgãos deste compartimento se deslocára.

o Prof. Miguel Couto e Dr. Eduardo Rodrigues Alves baseam a sua teoria nestas experiencias le no facto, já classico, de que a sonoridade á percussão das vertebras dorsais vae augmentando de cima para baixo, o mesmo sucedendo - emibora em menor escala - com a parede toracica posterior. Ora, si a sonoridade se incrementa de cima para baixa, é um corolario dizer-se que as vibrações 
de qualquer som - massiço, claro ou timpanico - nascidas de um hemitorax, são com mais facilidade transmitidas ao outro á medida. que se desce na coluna raquiana, e, portanto, vae aumentanço a distancía até onde são percebidos.

Consoante a sua doutrina, as causas de massicez - derrames liquidos, pneumonia, paquipleuriz, etc. - actuam dificultando as vibrações da coluna vertebral e da zona da parede toracica que lhe é immediata, ou, em outros termos, agem como abafadores de som. No pneumotorax fenomeno inverso sucede, e a cavidade pleural, repleta de ar, funciona como caixa de resonancia.

Assim, pois, o abafamento ou a caixa de nesonancia explicam perfeitamente a formação, respectivamente, de uma massicez ou de um timpanismo paravertebral, emquanto que a sua forma triangular é de sobejo aclarada pela circumstancia do raquis e aa porção visinha da arca toracica vibrarem, já em condições normaes, mais intensamente nas partes inferiores que nas superiores.

Em resumo, esta teoria nacional é a unica capaz de interpretar satisfatoriamente todos os factos atinentes ao triangulo de Grocco.

\title{
Leucemia monocytica ${ }^{(1)}$
}

\author{
Doutorando Ernesto de Souza \\ Campos (interno de clinica me- \\ dica)
}

Reschad e Schilling, pela primeira vez na litteratura hematologica, descreveram uma nova especie de leucemia a grandes mono-nucleares e formas de passagem - leucemia splenocytica.

Os autores, não obstante a sua competencia no assumpto, tiveram o cuidado de enviar preparados de sangue a Pappenheim e a Naegeli, os dois expoentes maximos da hematologịa moderna.

Pappenheim estabeleceu o diagnostico de monocytose electiva, em grau muito elevado e Naegeli, o chefe dos neo-dualistas, verificando que o preparado continha quasi somente cellulas do typo das normaes fórmas de passagem, admittiu uma leucemia a fórmas de passágem.

Faremos um breve resumo da interessante syndrome.

Symptomatologia e exame somatico. - Individuo com 33 annos de idade, em estado de grande prostração e inappetencia, com febre, gengivite, forte rhinorrhagia, diarrhéa, manchas por todo o corpo.

o exame, demonstrou pallidez do rosto e das gengivas, que estavam em parte ulceradas e facilmente sangrentas, hemorrhagias cutaneas, especialmente nas côxas e no thorax, epistaxis, baço accesivel á palpação, temperatura $38^{\circ}, 6$.

(1) Trabalho apresentado ao "Gremio dos Internos dos Hospitaes". 